\title{
Designing Mildred: Scaffolding Students' Reflection and Argumentation Using a Cognitive Software Guide
}

\author{
Philip Bell \\ University of Washington \\ 322 Miller Hall, Box 353600, Seattle, WA 98195-3600 \\ Tel: (206) 221-3642, Fax: (206) 543-8439 \\ Email: pbell@u.washington.edu
}

\author{
Elizabeth A. Davis \\ University of Michigan \\ 610 E. University Ave., Ann Arbor, MI 48109-1259 \\ Tel: (734) 647-0594, Fax: (734) 763-1368 \\ Email: betsyd@umich.edu
}

\begin{abstract}
In this paper, we discuss the design and study of a guidance and prompting system for a technology-based learning environment used in science classrooms. We focus briefly on how the tool has evolved through several years of iterative refinement, how the tool has been used by students in different curricular contexts for different epistemic practices, and how we as researchers can learn about students' learning and cognition through use of the affordances of such software environments. In particular, scaffolding in the form of prompts and hints are investigated for supporting causal explanations of scientific evidence (or argumentation) and promoting more general reflection. The results imply that both kinds of scaffolds support students' knowledge integration in important ways. The paper concludes with the claim that the guidance software helps students identify ways to improve their understanding by helping students think individually and collaboratively to provide alternative examples, thought experiments, and counter-evidence for consideration, and by providing a place to make their own thinking about these ideas visible and explicit. The paper also makes the broader claim that educational design studies such as the two reported here serve a unique role in identifying designed approaches that best support student learning while also informing our understanding of individual and social cognition in typical educational contexts.
\end{abstract}

Keywords: learning environments, scaffolding, science education, reflection

\section{Introduction}

In this paper, we describe our design of a guidance and prompting system for a technology-based learning environment used in science classrooms. We discuss how the tool is used by students in different curricular contexts, and how we as researchers can learn about students' learning and cognition through use of different affordances of the tool. The guidance system we investigate is part of the Knowledge Integration Environment (KIE). Using KIE, students complete projects drawing on scientific evidence from the World Wide Web (Bell, Davis, \& Linn, 1995). KIE blends custom and commercially-available software. The KIE software is used by students participating in curriculum units. Those units, called "projects," are designed to encourage a deep understanding of science concepts rather than memorization of a collection of scientific facts, and to help students apply the science principles they have been learning in class, integrate those principles with other knowledge, and extend their understanding to new situations. KIE projects come in three flavors. Critique projects foster the development of a critical eye when using evidence and evaluating arguments. Collaborative debate projects help students see that multiple perspectives and arguments may exist for a controversial topic, and that they can better understand and learn about the topic by constructing and collectively critiquing arguments involving relevant evidence. Design projects engage students in an application of their knowledge with decisions informed by scientific evidence. All three types of projects engage students in sustained reasoning: These projects help students develop an integrated understanding of science concepts while at the same time encouraging them to learn to think about and use scientific evidence.

The goal of instruction using KIE is knowledge integration, a process of linking, distinguishing, and reconciling ideas to develop a coherent and robust understanding. The knowledge integration perspective on learning is grounded in cognitive research that views learning as a process of integrating ideas (diSessa, 1988; Linn \& Eylon, 1996). Knowledge integration is a mechanism of conceptual change. This view needs to be contrasted with a replacement perspective on conceptual change—and the related cognitive conflict approach (cf. Chan et al., 1997, for a review) - in which students' non-normative ideas are viewed as "misconceptions" to be replaced or eradicated (e.g. McCloskey, 1983). An approach that takes the constructivist notion seriously would view students' experience-based conceptions as intellectual resources to build upon, rather than something to replace (Smith, diSessa, \& Roschelle, 1994). Knowledge integration can also be contrasted with the dissatisfaction view of conceptual change (Strike \& Posner, 1992), in which students must become dissatisfied with their current ideas, and see the new ideas as fruitful, 
intelligible, and plausible. Knowledge integration, on the other hand, sees less fruitful ideas as being applied less and less frequently, rather than being replaced. Knowledge integration is also different from theory change (Carey, 1988); from a knowledge integration perspective learners are viewed as linking what are often fragmented ideas and identifying contexts in which they are appropriate rather than revising explicit and well-formulated theories that learners apply generally.

Scaffolded knowledge integration is the instructional approach used to support knowledge integration. Students are scaffolded, or supported, as they integrate their ideas. The framework has grown out of 12 years of design studies and involves four elements (Linn, 1995; Linn \& Hsi, in press). First, instruction should "make thinking visible" to students by illustrating how links and connections are made. Teachers and students reasoning about scientific phenomena need to reveal their own thinking to themselves and their peers. Second, instruction should identify models for scientific phenomena that make sense to students so they can connect new information to existing knowledge and to problems that are both familiar and relevant. Third, instruction should provide social supports so all students learn new links and connections for their ideas from their peers. Finally, students should be encouraged to become autonomous learners so they can regularly revisit their ideas and continue to engage in knowledge integration.

\section{The Knowledge Integration Environment Software and Curriculum}

One component of the KIE software is a guidance-on-demand system called "Mildred" designed explicitly to help provide the support students need to integrate their ideas. Figure 1 shows this guidance software. Mildred provides hints at the level of project activities, evidence, and scientific claims. It also includes integrated note-taking functionality that prompts students to articulate their understanding about specific aspects of the project.

These features support the tenets of the scaffolded knowledge integration framework (Bell, 1998; Davis, 1998; Linn, 1995). For example, hints make expert thinking visible, and notes allow the students to make their own thinking visible. Hints also help students connect the science ideas to their own experiences; a typical hint might ask, "Have you ever experienced anything like this before?" or "What would happen if the experiment was done under different conditions?" As students work together on their project, Mildred also acts as a catalyst for getting students to talk to one another and exchange ideas. Last, by providing prompts for reflection and explanations, Mildred helps promote autonomy by enabling students to engage more freely in knowledge integration. These design decisions are based on particular pedagogical goals of KIE and in particular scaffold students as they engage in the sustained reasoning inherent in KIE projects.

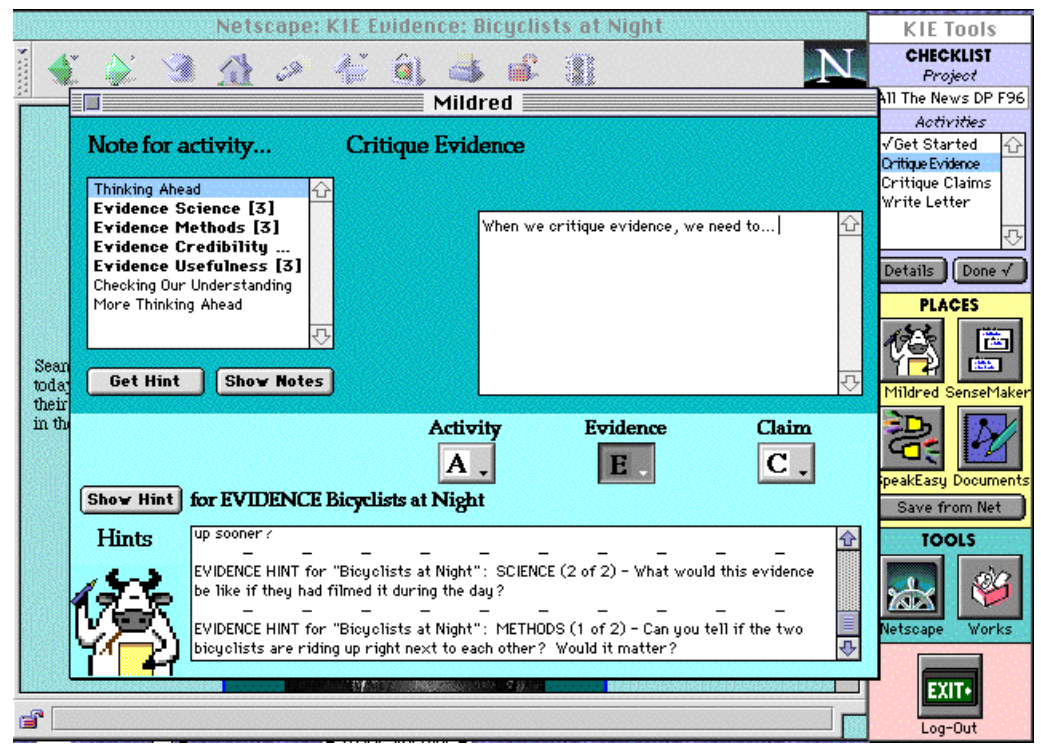

Figure 1. Mildred Guide in the Knowledge Integration Environment

Two projects will provide the context for the studies reported here-a critique project and a collaborative debate project. The instructional goals of the "All The News" critique project are two-fold. First, we want students to improve their understanding of the science concepts involved in the project. At the same time, we want them to develop an understanding of critiquing evidence and claims. In the All The News project, students critique evidence cited by a fabricated news article about energy conversion and elementary thermodynamics, topics they have studied 
in class in the weeks leading up to the project. The students are told that a "science tabloid" wants to become a respected science journal, and has requested the students' help in doing so. The project involves (a) reading the article to be critiqued and looking at its concomitant evidence about heat flow, energy conversion, and thermal equilibrium, (b) critiquing the evidence being used, (c) critiquing the claims being made, and (d) writing a letter to the imaginary editor with a synthesized critique and giving guidelines for future use of evidence. Thus, the four main activities include getting started, critiquing evidence, critiquing claims, and writing the letter.

The collaborative debate project gets students to explore "How Far Does Light Go?" Students are encouraged to refine their understanding of light developed over a five week light curriculum sequence leading up to the project. We want students to develop a more integrated understanding of light while also learning how to construct and debate arguments about the topic. In particular, students explore two theoretical perspectives: that light dies out over distance and the scientifically normative idea that light travels forever unless it is absorbed. As part of this project, students (a) explore a set of evidence to see how each piece relates to the two theories, (b) develop elaborated arguments based on this evidence, and (c) engage in a collaborative classroom debate leveraging off of the arguments they constructed. During the How Far project, students' ability to engage critically with the evidence builds on what they learned previously in the All The News critique project. Students are also supported in their construction and debate of scientific arguments by a software tool called SenseMaker that makes their individual and group thinking visible (Bell, 1998). Current analysis documents how this collaborative debate project promotes epistemological sophistication on the part of students.

The studies reported here took place in an eighth grade physical science class taught by an award winning veteran teacher. The class studied the topics of heat, temperature, and light for a full semester. All The News and How Far were two of the four or five KIE projects used during that time. Students work in pairs in this classroom.

\section{The Iterative Design of a Guidance System}

Over the course of several years, Mildred evolved from a fairly simplistic guidance system to an integrated resource where students could receive all the cognitive guidance built into the projects. Mildred's design was influenced by other successful learning environments including CSILE (Scardamalia \& Bereiter, 1991), CLP (Linn \& Songer, 1991), and others (e.g. Linn \& Clancy, 1992; Tabak et al. 1998). In this section, we review briefly Mildred's early design, and then move into a more detailed description of the system's current implementation.

Given the potential complexity of Web sites that students could be exploring in KIE projects and our knowledge of students' difficulty in interpreting computer help (Davis, Linn, \& Clancy, 1995), we realized immediately that it would be important to have a means by which to provide students with meaningful conceptual and strategic hints. One design issue related to integrating cognitive scaffolding into a learning environment relates to how the supports are made available to the students. Without having the system develop a comprehensive record of each student, we decided to integrate a range of scaffolds into KIE that were available on demand when requested by the students. This leaves students making judgments about when they might benefit from help though not necessarily what type of guidance would be the most beneficial at a particular point in their inquiry. When students desired help, the original Mildred software component provided students with hints about the evidence they were exploring, the activity they were working on in the project, and about the project overall. In a completely separate software component, students were prompted to take notes about the evidence. As we explored the use of the KIE software, we were able to further refine and integrate these software components. We also moved away from providing students with the high-level hints about the project, since they proved to be of little use.

Later versions of Mildred concentrate all cognitive guidance in one place. The current instantiation of Mildred provides three types of hints—on activities, evidence, and claims. For example, in the "Critique Evidence" activity of All The News, an activity hint might say, "When you critique the evidence, you will think about: (1) the science ideas used in the evidence, (2) the methods used to create the evidence, and (3) how credible or believable the evidence is." Further activity hints for the Critique Evidence activity would provide definitions and examples of the critique criteria of science, methods, and credibility. Evidence hints are more specific, providing help in thinking about a particular piece of evidence. A hint for the "Bicyclists at Night" evidence (used in both All The News and How Far) is, "Why is the person in white [clothes] easier to see? What is happening to the light?" A student working on a critique of the Bicyclists at Night evidence could then receive converging evidence on both the act of critiquing and the specific evidence being critiqued. Likewise, claim hints help students think about a particular claim. For example, a claim hint about black "attracting heat" (as opposed to absorbing light) might say, "What would happen if there were a heat source in a dark room? Would someone wearing black get hotter than someone wearing white?" 
Mildred includes four basic types of notes, including notes focused on activities, evidence, and claims, as well as notes that prompt students for reflection. Mildred prompts students to take notes using sentence-starter prompts; students may write one or several sentences. Students may change the wording of the prompts, though typically they do not do so.

Activity notes focus students' attention on particular tasks involved in an activity. For instance, in the How Far project's Create Evidence activity, the prompts for the activity note for creating a piece of evidence to support the Light Dies Out theory are, "Our LDO evidence is... The specific reason that our evidence is relevant to the debate is because...." Evidence notes focus instead on aspects of the evidence students are reviewing. For example, the prompt for an evidence note in the Critique Evidence activity of All The News says, "How good are the methods for this evidence? The methods for this evidence...." Claim notes are similar to evidence notes, except they are instead specific to claims or theories. In All The News' Critique Claims activity, the prompt for a claim note says, "In thinking about how to change this claim to be more valid, we think..." A prompt for a claim note in How Far, on the other hand, might say, "Summarize what you think each theory means and rate how valid you think it is. This

theory says...." In the How Far project, students create arguments that are quite complex based on their evidence and claim notes (as discussed in the Results section).

The last type of notes encourage students to be more reflective. Mildred gives two types of reflection prompts. The first type, called generic prompts, represents a view that asking students to "stop and think" will encourage reflection. An example of a generic prompt (in either project) is, "Right now, we're thinking...." The second type, called directed prompts, assumes that students need guidance in determining how to reflect. Mildred gives directed prompts oriented toward planning and monitoring: Thinking Ahead prompts encourage planning for future activities, while Checking Our Understanding prompts ask students to monitor their understanding. An example of a Checking Our Understanding directed prompt from All The News is, "Pieces of evidence we didn't understand very well included...."

\section{Results}

A full discussion of students' use of Mildred is outside the scope of this paper. Instead, we focus in particular on students' use of evidence notes and reflection prompts.

\section{Using Evidence Notes to Support Argumentative Practices}

A central epistemic practice in science is being able to coordinate theoretical notions with empirical evidence. We wondered if we could scaffold students in coordinating scientific evidence with theory using KIE. During the How Far project, students are charged with developing an argument about the debate topic. Students spend approximately five days developing explanations about how each piece of evidence is related to the various theoretical positions of the debate. Based on previous research in developmental psychology (e.g., Kuhn, 1993), we might question whether students would be able to adequately coordinate theory and evidence as they construct their arguments. This research has indicated that students rarely coordinate evidence and theory spontaneously. However, in working on KIE projects students receive numerous forms of scaffolding to support their engagement in argumentation. For details of this study, see Bell $(1997,1998)$.

Students' evidence explanations were coded and analyzed to determine whether students were calling upon or trying to establish warrants (i.e., causal conjectures) about the evidence provided, or if they were simply dealing with the light-related evidence in a phenomenological or descriptive manner-a common occurrence when students learn about light (Reiner, Pea, \& Shulman, 1995). Table 1 summarizes the coded evidence explanations that students constructed in the Mildred software. As indicated, each explanation is quite long-about 69 words in length, on average. The evidence explanations consisted primarily of causal warrants (80\%); only $16 \%$ were simply descriptive. One of the pieces of evidence investigated related to night-vision goggles. A descriptive response to this evidence would state that "the goggles can help you see things at night." A causal warrant for the same evidence would perhaps explain how "the binoculars collect and magnify the little bit of light reaching them." The warrants were further analyzed for being congruent with the instructional conceptual model of light (or partially so), deriving from some other causal model invoked by the student, or consisting of a mixture of the two. Half of the evidence explanations analyzed made some reference to the instructed light model associated with the curriculum. It should be noted that the usefulness of the "other" causal warrants are dependent on the details of the model invoked; these responses should not be assumed automatically to be less productive in the context of the project, but rather were just not associated with the instructed conceptual model embedded in the curriculum. 
Table 1. Summary of Coded Dimensions of Student Evidence Explanations $(\mathrm{N}=910)$

\begin{tabular}{lrc}
\hline Evidence Explanations & Mean & Std. Dev. \\
\hline & & \\
Total Explanations per group (out of 13 possible) & 10.3 & $(2.3)$ \\
Average Explanation Length (in words) & 68.6 & $(34.7)$ \\
& & \\
Percentage of Warrants & $79.5 \%$ & $(15.7 \%)$ \\
$\quad$ Full Instructed Model Responses & $19.2 \%$ & $(17.6 \%)$ \\
$\quad$ Partial Instructed Model Responses & $30.2 \%$ & $(17.2 \%)$ \\
$\quad$ Mixed Model Responses & $14.4 \%$ & $(13.0 \%)$ \\
$\quad$ Other Causal Model Responses & $15.7 \%$ & $(13.1 \%)$ \\
Percentage of Descriptions & $16.2 \%$ & $(14.5 \%)$ \\
Percentage of Irrelevant & $4.2 \%$ & $(6.6 \%)$
\end{tabular}

Without scaffolding, students are less likely to attempt coordinating evidence with theory. The results here indicate that students were primarily tethering the evidence to the debate by relying upon their prior knowledge about light (a warrant-using move) or by conjecturing about light in some causal manner (a warrant-establishing move). In other words, when students received the scaffolding provided by the KIE instruction and the Mildred software, they could successfully coordinate scientific evidence with theory. We turn now to an investigation of the scaffolding provided to support students' reflection.

\section{Using Reflection Prompts to Promote Critique Practices}

Historically, researchers have highlighted the importance of encouraging students to reflect (e.g. Bloom, 1956; Brown, Bransford, Ferrara, \& Campione, 1983; Rothkopf, 1966). Pilot work (Davis \& Linn, in press) led us to wonder whether students mainly need to be reminded to reflect, or if they need guidance in identifying productive avenues for reflection. A study of students' use of directed and generic reflection prompts in the context of the All The News project investigates this question. The study contrasts the reflection and learning outcomes of students in two conditions: one receiving directed prompts and the other receiving generic prompts. (Students also experienced more explanation-oriented evidence and claim notes similar to those described in the previous section.) In keeping with the idea of scaffolding, explicitly telling students what to reflect on seems sensible. On the other hand, being too directive may derail or constrain some students' thought. Outcome measures include the kinds of ideas students cite in discussing claims and evidence, the coherence of their science ideas, and the quality of their critiques. Students' reflection is also characterized. For details of the study, see Davis (1998); highlights are reported here.

First, students who received generic prompts cited significantly more ideas in their claim notes than did students who received directed prompts $(\mathrm{t}[87]=-2.448, \mathrm{p}=.0164)$. Second, students in the generic prompt condition were significantly more likely to display highly coherent ideas than were those in the directed prompt condition-approximately twice as many students who received generic prompts were in the higher coherence group (Fisher's Exact $\mathrm{p}=.0492$ ). To illustrate coherence, one pair of students who wrote a coherent explanation of energy conversion cited three principles, all of which were scientifically valid and match the instructed model. Another pair, on the other hand, cited six internally contradictory principles-that black attracts heat, black attracts light, black absorbs heat, white reflects heat, white reflects light, and light can be converted to heat. (The last two listed comprise part of the instructed conceptual model; the first four do not.)

Third, factorial ANOVAs indicate that students who received directed prompts were non-reflective significantly more often than were those in the generic prompt condition $(F[1,89]=14.000, p=.0003)$. Students were then categorized as reflectors or non-reflectors based on their responses to prompts. A non-reflective pair responded to a directed prompt in the following way: "Claims in the article we didn't understand very well included... none, we understood them all." This response is typical of the non-reflective students. A different pair of students responded to a generic prompt in a more reflective way, writing, "Our ideas right now are... that the article could be changed to sound right, and actually be correct, if the authors looked over the evidence closer before making their claims." ANOVA analysis indicates that highly non-reflective students responding to directed prompts achieved significantly lower critique quality scores than did (a) reflective students (effect size $85 \%$, for comparison with reflective directed prompt responders) or (b) students who were non-reflective in response to generic prompts (effect size $78 \% ; F[1,1,1,85]=4.757, \mathrm{p}=.0319$ for the interaction between non-reflective responses and condition). 
Thus, generic prompts appear to encourage productive activities and to foster both reflection and knowledge integration.

Generic prompts allow-in fact, force-students to reflect in their own 'default' ways. These defaults may be, for many students, more useful than our best-intentioned direction; most students appear capable of productively taking charge of their own reflection. In contrast to directed prompts, generic prompts do not generally enable students to be "cognitive economists"—-students who do the minimal amount of cognitive work (Linn, Songer, \& Eylon, 1996). If they manage to identify weaknesses in their current knowledge, students responding to generic prompts may begin to distinguish among ideas and link those ideas both within their responses to the generic prompts themselves, and, more often, in aspects of the project. Since generic prompts appear to help students expand their repertoire (through eliciting more ideas) and identify weaknesses in their existing knowledge (by forcing some kind of reflection rather than allowing non-reflective answers), students in the generic prompt condition appear to have more opportunities to integrate their knowledge. And in fact, students responding to generic prompts developed a more coherent, integrated understanding of the science concepts than did other students.

\section{Conclusions}

We can view these results from the perspective of instructional designers and of cognitive researchers. From the instructional designer perspective, we see that the Mildred guidance system works effectively to scaffold students' knowledge integration in these two different curricular contexts through encouraging explanation, argumentation, and reflection. Then, from the perspective of cognitive research, we see that we can learn a great deal about students' knowledge integration from their use of the tool.

There are several important implications of this dual-focused research. First, cognitive scaffolding embedded in a software guide was able to support important practices for science learning (critiquing and argumentation). It should be noted that as designers of such tools and experiences, we are attempting to understand while also arranging the various epistemological forces at work in these settings (see diSessa, 1995 for a discussion of epistemological forces). As researchers we needed to develop a contextualized understanding of the cognition that was emergent and that was desired connected with the use of Mildred so that we could further refine the design. Understanding the nature of reflection and argumentation possible with these students was crucial to understanding how to make effective use of the Mildred software. It is important to note that it was not the Mildred software alone contributing to these cognitive practices; the How Far and All The News projects involved the coordination of a 'package of innovation' in order for them to be successful (see Salomon, 1996, for details on the package-like nature of innovation). In particular, the teacher is a crucial component of the instruction here. The effects described should not be simply attributed only to the software and curriculum.

A second implication of this work focuses on how a discipline-specific but subject matter-general software component can be used to support desired forms of cognitive activity when it is embedded in particular curricula. Although the Mildred software depends upon philosophical features of science represented in the KIE ontology (e.g., evidence and claims), the software design is general with regard to specific subject matter. The same tool can be (and is) used with different subject matter in various projects. The instructional use of Mildred is complex in that we find both domain-general (e.g. generic prompts for reflection) and domain-specific (e.g. explanation-focused evidence notes) prompts and hints to be helpful and, perhaps, necessary. Students may benefit from different emphases in different instructional contexts like debating and critiquing; still, the same affordances of the tool support these varied cognitive activities. Once again, we are reminded that contextual details matter. The capability to orchestrate different types of scaffolding through the same piece of guidance software was beneficial to students' knowledge integration. Generic prompts for reflection foreground the students' own reflection and kick-start the knowledge integration process of identifying weaknesses in their knowledge - but these prompts cannot succeed in fostering that knowledge integration on their own. Only with highly specific scaffolds for causal explanations-along with the other important scaffolding in the learning environment as a whole—do students develop the warranted explanations that can also contribute to their knowledge integration.

Mildred fosters knowledge integration by helping students add ideas to their repertoires (through hints and through the exchange of ideas via conversations with others) and link, distinguish, and reorganize ideas (through prompts and hints). In particular, Mildred helps students identify weaknesses in their knowledge by providing alternative examples, thought experiments, and counter-evidence to consider, and by providing a place to make their own thinking about these ideas visible and explicit. We believe such designs are possible only when aspects of design are attended to in coordination with empirical studies of learning and cognition (Brown, 1992; diSessa, 1991). These 'educational design studies' can serve a unique role in identifying approaches that best support student learning. 


\section{References}

Bell, P. (1997). Using argument representations to make thinking visible for individuals and groups. In R. Hall, N. Miyake, \& N. Enyedy (Eds.), Proceedings of CSCL '97: The Second International Conference on Computer Support for Collaborative Learning (pp. 10-19). Toronto, Canada: University of Toronto Press. Available on-line: http://www.oise.utoronto.ca/cscl/papers/bell.pdf.

Bell, P. (1998). Designing for students' science learning using argumentation and classroom debate. Unpublished doctoral dissertation, University of California, Berkeley, CA.

Bell, P., Davis, E. A., \& Linn, M. C. (1995). The Knowledge Integration Environment: Theory and design, Proceedings of the Computer Supported Collaborative Learning Conference (CSCL '95: Bloomington, IN), (pp. 14-21). Mahwah, NJ: Lawrence Erlbaum Associates.

Bloom, B. S. (1956). Taxonomy of educational objectives: The classification of educational goals. (Vol. Handbook 1: Cognitive Domain). New York: David McKay Company, Inc.

Brown, A. L. (1992). Design Experiments: Theoretical and Methodological Challenges in Creating Complex Interventions in Classroom Settings. The Journal of the Learning Sciences, 2(2), 141-178.

Brown, A. L., Bransford, J. D., Ferrara, R. A., \& Campione, J. C. (1983). Learning, remembering, and understanding. In P. H. Mussen (Ed.), Handbook of child psychology: Cognitive development (Vol. III, ). New York: Wiley.

Carey, S. (1988). Conceptual differences between children and adults. Mind and Language, 3(3), 167-181.

Chan, C., Burtis, J., \& Bereiter, C. (1997). Knowledge building as a mediator of conflict in conceptual change. Cognition and Instruction, 15(1), 1-40.

Davis, E. A. (1998). Scaffolding students' reflection for science learning. Unpublished doctoral dissertation, University of California, Berkeley, CA.

Davis, E. A., \& Linn, M. C. (in press). Scaffolding students' knowledge integration: Prompts for reflection in KIE. International Journal of Science Education.

Davis, E. A., Linn, M. C. \& Clancy, M. J. (1995). Students' off-line and on-line experiences. Journal of Educational Computing Research, 13(2).

diSessa, A. A. (1988). Knowledge in pieces. In G. Forman \& P. Pufall (Eds.), Constructivism in the Computer Age (pp. 49-70). Hillsdale, NJ: Erlbaum.

diSessa, A. A. (1991). Local sciences: Viewing the design of human-computer systems as cognitive science. In J. M. Carroll (Ed.), Designing Interaction: Psychology at the Human-Computer Interface, (pp. 162-202). Cambridge, England: Cambridge University Press.

diSessa, A. A. (1995). Epistemology and systems design. In A. A. diSessa, C. Hoyles, R. Noss, and L. Edwards (Eds.), Computers and Exploratory Learning. Berlin: Springer Verlag.

Kuhn, D. (1993). Connecting scientific and informal reasoning. Merrill-Palmer Quarterly, 39(1), 74-103.

Linn, M. C. (1995). Designing computer learning environments for engineering and computer science: The scaffolded knowledge integration framework. Journal of Science Education and Technology, 4(2), 103-126.

Linn, M. C., \& Clancy, M. J. (1992). Can experts' explanations help students develop program design skills? International Journal of Man-Machine Studies, 36(4), 511-551.

Linn, M. C., \& Eylon, B.-S. (1996, July). Lifelong science learning: A longitudinal case study. Paper presented at the Cognitive Science Conference, San Diego, CA.

Linn, M. C. \& Hsi, S. (in press). Computers, Teachers, Peers: Science Learning Partners. Mahwah, NJ: LEA.

Linn, M. C., \& Songer, N. B. (1991). Teaching thermodynamics to middle school students: What are appropriate cognitive demands? Journal of Research in Science Teaching, 28, 885-918.

Linn, M. C., Songer, N. B., \& Eylon, B. S. (1996). Shifts and convergences in science learning and instruction. In R. Calfee \& D. Berliner (Eds.), Handbook of educational psychology (pp. 438-490). New York: Macmillan.

McCloskey, M. (1983). Naive theories of motion. In D. Gentner \& A. L. Stevens (Eds.), Mental Models (pp. 299324). Hillsdale, NJ: Lawrence Erlbaum Associates.

Reiner, M., Pea, R. D., \& Shulman, D. J. (1995). Impact of simulator-based instruction on diagramming in geometrical optics by introductory physics students. J. of Science Educ. and Technology, 4(3), 199-226.

Rothkopf, E. (1966). Learning from written instructive materials: An Exploration of the control of inspection by test-like events. American Educational Research Journal, 3, 241-249.

Salomon, G. (1996). Studying novel learning environments as patterns of change. In S. Vosniadou, E. D. Corte, R. Glaser, \& H. Mandl (Eds.), International Perspectives on the Design of Technology-Supported Learning Environments, (pp. 363-377). Mahwah, NJ: LEA. 
Scardamalia, M., \& Bereiter, C. (1991). Higher levels of agency for children in knowledge building: A challenge for the design of new knowledge media. The Journal of the Learning Sciences, 1, 37-68.

Smith, J. P., diSessa, A. A., \& Roschelle, J. (1994). Misconceptions reconceived: A constructivist analysis of knowledge in transition. The Journal of the Learning Sciences.

Strike, K., \& Posner, G. (1992). A revisionist theory of conceptual change. In R. Duschl \& R. Hamilton (Eds.), Philosophy of Science, Cognitive Science, and Educational Theory \& Practice . Albany, NY: SUNY Press.

Tabak, I., Sandoval, W., Smith, B., Steinmuller, F., \& Reiser, B. (1998, April 16). BGuILE: Facilitating reflection as a vehicle toward local and global understanding. Paper presented at the American Educational Research Association conference, San Diego, CA.

\section{Acknowledgments}

This material is based upon research supported by the National Science Foundation under grant Nos. RED-9453861 and MDR-9155744. Any opinions, findings, and conclusions or recommendations expressed in this publication are those of the authors and do not necessarily reflect the views of the National Science Foundation. We appreciate the interest and cooperation of the middle school students who made the research reported here possible. We thank Marcia C. Linn for her ongoing support in working on this research and the other members of the KIE (http://www.kie.berkeley.edu/KIE.html), CLP (http://www.clp.berkeley.edu/CLP.html), and WISE (http://wise.berkeley.edu/WISE/) research groups at the University of California, Berkeley. 